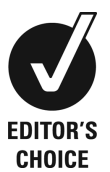

CHOICE

\title{
Christmas disease: diagnosis and management of a haemorrhagic diathesis following dentofacial trauma
}

\author{
Sridevi B Tamagond, ${ }^{1}$ Santosh I Hugar, ${ }^{2}$ Anil Patil, ${ }_{1}^{1}$ SandhyaRani Huddar ${ }^{1}$
}

${ }^{1}$ Department of Pedodontics, Bharati Vidyapeeth Deemed University Dental College and Hospital, Sangli, Maharashtra, India

${ }^{2}$ Department of Conservative Dentistry, Bharati Vidyapeeth Deemed University Dental

College and Hospital, Sangli, Maharashtra, India

\section{Correspondence to} Dr Anil Patil,

dranilp0888@gmail.com

Accepted 19 December 2014

\section{SUMMARY}

Haemorrhagic diathesis has been of much concern to health professionals including dentists. It is not infrequent that a dentist becomes the first person to diagnose a bleeding disorder while performing dental treatment. Haemophilia is an $X$ linked disorder with a frequency of about 1:10 000 births. Haemophilia $B$ is much less common than haemophilia $A$, and affects only 1:300 000 males born alive. The clinical features of haemophilia $B$ are very similar to those of haemophilia $A$ with a prolongation of activated partial thromboplastin time. This case report describes the dental management of a patient with an uncommon haematological disorder, namely, factor IX deficiency, which remained undiagnosed until the patient had to undergo dentofacial trauma with unexpected severe haemorrhage. Preventive dentistry remains vital to young haemophiliacs. Surgical dental procedures may be performed for haemophiliacs but they must be judiciously coordinated by dental and medical health professionals.

\section{BACKGROUND}

Haemorrhagic diatheses are conditions that alter the ability of blood vessels, platelets and coagulation factors to maintain haemostasis. ${ }^{1}$ Haemophilia is an $\mathrm{X}$ linked disorder with a frequency of about $1: 10000$ births. $^{2}$ It is characterised by three chief forms described as haemophilia A (classic haemophilia), in which there is deficiency of factor VIII; haemophilia B (Christmas disease), characterised by deficiency of factor IX; and haemophilia C, caused by deficiency of plasma thromboplastin antecedent. ${ }^{3}$ Haemophilia B is much less common than haemophilia $\mathrm{A}$, and affects only 1:300 000 males born alive. ${ }^{4}$

Diagnosis of haemophilia is based on brief medical history, clinical examination and laboratory investigations. Medical history should include history of bleeding after previous surgery or trauma, drug history, family history of bleeding abnormalities and symptoms associated with potential bleeding disorders. Diagnostic laboratory investigations in haemophilia $\mathrm{B}$ can be a prolonged activated partial thromboplastin time (aPTT), normal bleeding time (BT), normal prothrombin time (PT) and low factor IX. A factor IX assay is generally required because even the aPTT may be normal in mild cases. A few patients with haemophilia B present an abnormal factor IX that slightly prolongs the $\mathrm{PT}^{4}$ Haemophilia B is considered severe when levels of factor IX plasma activity are $<1 \%$; moderate if they range between $1 \%$ and $5 \%$, and mild if they are between $5 \%$ and $40 \% .^{3}$ Haemophilia $\mathrm{C}$ is a milder form of haemophilia due to factor XI deficiency and, unlike haemophilia $A$ and B, affects both sexes. Even in severe deficiency of factor XI, the bleeding tendency is mild, making haemophilia $\mathrm{C}$ more difficult to manage than haemophilia A or B. ${ }^{5}$

The clinical features of haemophilia usually become apparent when the child begins to crawl. The most common problems are spontaneous bleeding in the joints, elbows or knees. This may lead to chronic deformity of the joint with swelling and pain. ${ }^{1}$ Haemophilia also has effects on the orofacial complex. Patients with haemophilia may neglect their oral hygiene because of bleeding during brushing of teeth. ${ }^{6}$

\section{CASE PRESENTATION}

An 8-year-old boy presented to the department of paediatric dentistry at A. J. Institute of Dental Sciences, Mangalore, from where he was referred to our clinic with a suspected diagnosis of haemophilia. Although no similar family history was present, the patient had a history of prolonged bleeding after exfoliation of maxillary anterior deciduous teeth. The patient had hurt his mouth while playing 1 week before reporting to our clinic. Haematoma, swelling and slight laceration of soft tissue were present in the premaxillary region in association with erupting 11, 21 (figures 1 and 2). He was under outpatient observation immediately after the injury by a physician for 2 days where he was prescribed antibiotics and analgaesics, but the bleeding was not controlled. Later, the patient was monitored in the intensive care unit for 3 days at A. J. Institute of Medical Sciences, where he was given $10 \mathrm{mg}$ of tranexamic acid, an antifibrinolytic agent, intravenously, and an epinephrine-soaked gauze was placed on the clot.

On general examination, the patient appeared pale and lethargic. On intraoral examination, haematoma and swelling were seen relating to partially erupting maxillary central incisors. The

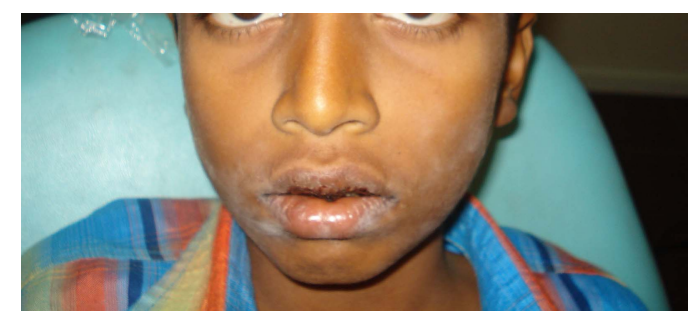

Figure 1 Extraoral photograph. 
Figure 2 Intraoral view showing haematoma, swelling and laceration of soft tissue in premaxillary area.
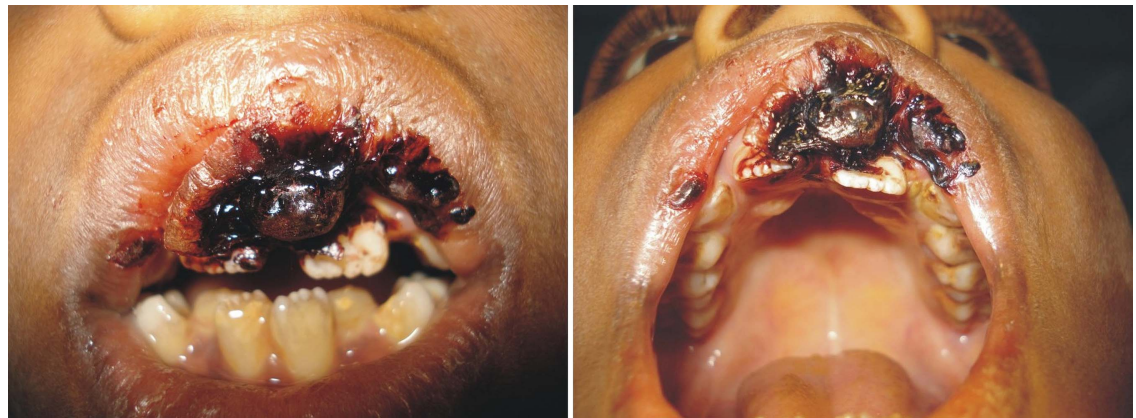

haematoma was blackish-red in colour. On dislodgement of the clot, bleeding was seen at the boundaries between the clot and normal gingival tissue. The maxillary central incisors were grade I mobile and bleeding was seen from the gingival sulcus of the respective teeth, and, on percussion, the maxillary incisors were tender. Intraoral radiographic examination revealed incompletely formed roots of all the maxillary incisors (figure 3).

\section{INVESTIGATIONS}

Tests used to evaluate bleeding diathesis:

- Complete blood count;

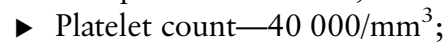

- BT-12 min;

- PT-normal;

- aPTT-prolonged;

- Clotting factor test-factor VIII activity was normal and factor IX concentrate was $1 \%$.

\section{DIFFERENTIAL DIAGNOSIS}

Factor IX activity was $1 \%$, which confirmed the diagnosis of haemophilia B under 'moderate' category.

\section{TREATMENT}

Blood reports revealed evidence of microcytic hypochromic anaemia, for which an oral iron supplement was prescribed. Plasma derived factor IX replacement therapy was administered

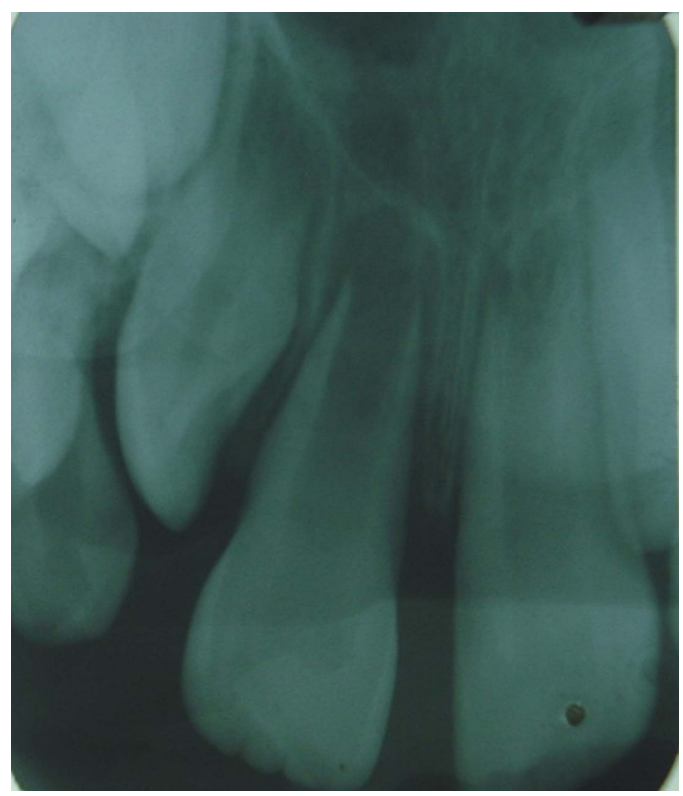

Figure 3 Preoperative intraoral periapical radiograph of 11, 21. by a haematologist. Complete oral prophylaxis and topical fluoride application were performed followed by dietary and oral hygiene instructions (figures 4 and 5). Cold liquid or semisolid diet was advised for the postoperative week. Antibiotics were prescribed as they would lessen the late bleeding caused due to infection. As non-steroidal anti-inflammatory drugs can aggravate bleeding, ${ }^{7}$ the safer substitute, acetaminophen, was prescribed.

\section{OUTCOME AND FOLLOW-UP}

The patient was on observation for 15 days for haematoma formation (figure 5). Child and parental counselling for prevention of dentofacial trauma were given. Also, use of sports mouthguards was encouraged. The importance of having routine dental check-ups, and of using oral prophylaxis and topical fluoride was restated to the parents for future follow-up.

\section{DISCUSSION}

Although teeth normally erupt and exfoliate naturally, in the event of a problem, non-invasive dental procedures are safe in patients with bleeding disorders, but may, in haemophiliacs, present a challenge to giving local anaesthetic injections and in carrying out oral surgical procedures. Local anaesthetic injections may lead to persistent bleeding for days or weeks; this type of haemorrhage cannot be controlled by mere pressure and may be life-threatening. Intraligamentary, intrapulpal or intraosseous injections or infiltrations are considered $\mathrm{safer}^{8}$ as compared with block anaesthesia. Electronic anaesthesia can be used along with hypnosis for alternative pain control. ${ }^{9}$ Surgeries must be carefully planned and performed with minimal trauma to soft tissues and bone. The chief concern is bleeding into the tissues, especially into a submandibular space, and the risk of consequent airway obstruction. Suturing should be performed with a non-traumatic needle and a minimum number of sutures must be used to stabilise the margins of flaps. With the decline of tonsillectomy for young children and teenagers, the commonest first surgical procedure children often have is a dental extraction. If the extraction results in unexpected postoperative bleeding, the astute clinician should be alerted to the fact that the child may be having a congenital haemorrhagic diatheses that should be investigated. Appropriate communication is needed between the physician and the dentist to perform safe and complete dental care. Education of parents regarding preventive dental care should be initiated as early as possible.

The interaction between the physician (haematologist) and dentist is an essential part of haemophilia management with or without the presence of trauma. The dentist's role in haemophilia care involves maintaining accurate knowledge of the patient's factor level, bleeding history, type of factor product used and the number of required infusions per year. ${ }^{10}$ Relatively 
Figure 4 Follow-up after 4 days showing bleeding points after dislodgement of clot.
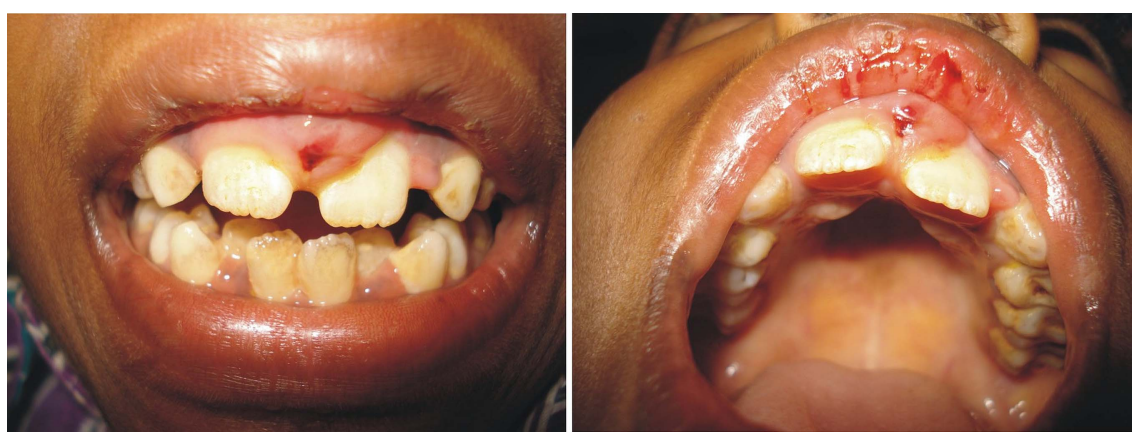

minor invasive procedures may precipitate prolonged bleeding that can delay completion of the procedures, compromise wound healing and predispose to infection. The bleeding risk of a dental procedure varies depending on the ease of access to the site and the application of local haemostatic measures.

When bleeding starts or is expected, factor IX should be restored to a level adequate to ensure haemostasis. Using fresh or frozen plasma with cryoprecipitate or fractionated human factor concentrates carries the risk of transmitting bloodborne infections such as HIV or hepatitis virus. ${ }^{11}$ Replacement of factor IX can be carried out using plasma-derived factor IX or recombinant factor IX. One unit of factor concentrate per kilogram of body weight increases the factor level by $2 \%$. Therefore, a formula can be stated as: ${ }^{12}$

$$
\begin{aligned}
\text { Dose to be infused }(\text { Units })= & \{\text { Weight of Patient }(\text { Kg }) \\
& \times \text { Increment needed }(U / d L)\} / 2
\end{aligned}
$$

Factor IX replacement therapy should retain $20-40 \%$ minimum circulating factor levels necessary for haemostasis during minor surgical and healing phases. It can be achieved by intermittent or continuous intravenous replacement therapy or using an antifibrinolytic with a single concentrate. Prophylactic cover for surgeries for haemophiliacs necessitates normal factor level maintenance for 1 week, then reduced dosage during recovery. This can be accomplished with repeated bolus injections 12 hourly or by continuous infusion. ${ }^{12} \mathrm{~A}$ pharmacokinetically tailored recombinant factor IX dose is necessary for treating haemophilia B cases. Only one recombinant factor IX product is licensed to treat haemophilia B cases, and that is nonacog alfa (BeneFIX; Pfizer, Sandwich, UK). ${ }^{13}$ It is a single-chain glycoprotein with a molecular mass of approximately $55000 \mathrm{Da}$ with a primary 415 -amino-acid sequence similar to the Ala148 allelic form of plasma-derived factor IX.

Clot maintenance is essential in haemophilia care, ${ }^{10}{ }^{14}$ as early breakdown or insufficient clot stabilisation will lead to

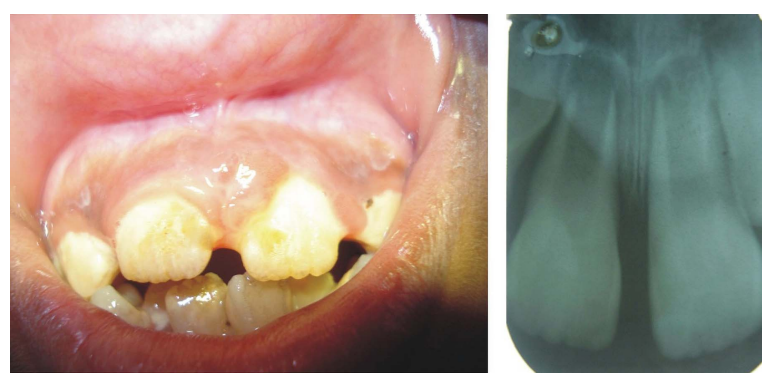

Figure 5 Follow-up after 15 days showing healing of wound and postoperative intraoral radiograph of 11,21 . continuous bleeding. This can be avoided by ensuring sufficient factor replacement postoperatively by a haematologist. For a simple extraction, local haemostatic measures such as pressure or topical agents can usually be applied to the potential site(s) of haemorrhage. Conventional local measures to control haemorrhage include: antifibrinolytics, topical thrombin, topical tranexamic acid (10\%) suspension and haemostatic pads. ${ }^{14}$ These local measures allow for maturity of the clot and the initial phases of wound healing, ${ }^{15}$ Topical thrombin is successful in some clinical situations but must come in direct contact with the bleeding site. ${ }^{14} 16$ This can be difficult intraorally in the presence of blood, saliva and muscular movements. Often a clot forms but bleeding continues beneath it. The use of thrombin is more successful when used under pressure with carrier mechanisms such as gauze or a collagen pad. ${ }^{17}$ Complications in the treatment of haemophilia can be described as dental neglect imposing extractions, factors VIII and IX inhibitors, local anaesthesia injections-related problems, threat of hepatitis B and liver disease, and HIV infection. ${ }^{4}$

In the present case, an epinephrine pack, which was not found to be useful, was employed topically to control the haemorrhage. However, tranexamic acid IV that was given was helpful. Some minor procedures with a low risk of bleeding can be performed without systemic haemostatic therapy; however, for the higherrisk procedures (extractions and oral surgery), appropriate systemic haemostatic cover may need to be considered and should be managed in consultation with a Haemophilia Treatment Centre (HTC) or haematologist. ${ }^{2}$

The age when haemophilia B is first diagnosed in a child, as well as the frequency of bleeding episodes the child experiences, is generally related to factor IX clotting activity. In haemophilia cases, bleeding episodes may be more frequent in childhood and adolescence than in adulthood. This greater frequency is a function of physical activity levels and vulnerability during more rapid growth. ${ }^{18}$ Preventive and restorative dentistry are of paramount importance in haemophilia cases as early dental treatment minimises the need for further invasive treatment and its complications. Prevention of bleeding episodes should be a primary objective. This also involves treating bleeding episodes early and aggressively. During restorative procedures, isolation with a rubber dam improves visibility and furthermore reduces the potential risk of laceration of the buccal mucosa and lips. Crowns should be placed with a smooth margin to avoid impingement on the gingival sulcus. The coordination of systemic therapies is handled by the physician, but local management often remains in the hands of the dentist. ${ }^{16}$ Decisions must consider the nature and severity of the patient's bleeding risk as well as the type, location, extent of the dental procedure, expertise and experience of the treating dentist. $^{2}$ 


\section{Learning points}

- There are numerous challenges in providing oral health services for patients with haemorrhagic diatheses of any cause.

- Thorough knowledge of screening tests, clinical features and precautions are vital to chart out an effective treatment plan for children with coagulation disorders.

- The paediatric dentist must have a comprehensive understanding of the disease and empathy towards such special children, which will go a long way in effective dental treatment.

\section{Competing interests None.}

Patient consent Obtained.

Provenance and peer review Not commissioned; externally peer reviewed.

\section{REFERENCES}

1 Little JW, Falace DA, Miller CS, et al. Bleeding disorders. In: Dental management of the medically compromised patient. 7th edn, Elsevier, St. Louis; 2008:396-432.

2 Israels S, Schwetz N, Boyar R, et al. Bleeding disorders: characterization, dental considerations and managements. J Can Dent Assoc 2006;72:827.

3 White GC II, Rosendaal F, Aledort LM, et al.; Factor VIII and Factor IX Subcommittee. Definitions in hemophilia. Recommendation of the scientific subcommittee on factor VIII and factor IX of the scientific and standardization committee of the International Society on Thrombosis and Haemostasis. Thromb Haemost 2001;85:560.
4 Scully C, Cawson RA. Medical problems in dentistry. 5th edn. London: Butterworth-Heinemann, 2004.

5 Bolton-Maggs PH, Prasad M, Hemophilia C. Medscape. Updated 22 August 2013. http://emedicine.medscape.com/article/955690-overview (accessed 4 Sep 2014).

6 Patton LL. Bleeding and clotting. In: Greenberg MS, Glick M, eds. Burket's oral medicine diagnosis and treatment. 10th edn. Hamilton: BC Decker, 2003:454-78.

7 Kumar JN, Kumar RA, Varadarajan R, et al. Specialty dentistry for the hemophiliac: Is there a protocol in place? Indian J Dent Res 2007;18:48-54.

8 Rakocz M, Mazar A, Varon D, et al. Dental extractions in patients with bleeding disorders. The use of fibrin glue. Oral Surg Oral Med Oral Pathol 1993;75:280-2.

9 Lombard J. Root canal hemorrhages in endodontics: a preventive solution. Chir Dent Fr 1976:46:45-51.

10 Kats JO, Terezhalmy GT. Dental management of the patient with hemophilia. Oral Surg Oral Med Oral Pathol 1988;166:139-44.

11 Scully C, Watt-Smith P, Dios RD, et al. Complications in HIV-infected and non-HIV infected haemophiliacs and other patients after oral surgery. Int I Oral Maxillofac Surg 2002;31:634-40.

12 Hoffbrand VA, Catovsky D, Edward GD, et al. Post graduate haematology. 5th edn. London: Blackwell Publishing, 2005.

13 Monahan PE, Di Paola J. Recombinant factor IX for clinical and research use. Semin Thromb Hemost 2010;36:498-509.

14 Evans BE. Dental management. In: Hilgartner MW, Pochedly C, eds. Hemophilia in the child and adult. 3rd edn. New York: Raven Press, 1989:89-119.

15 Durham TM, Hodges ED, Harper J, et al. Management of traumatic oral-facial injury in the haemophiliac patient with inhibitor: case report. Paediatr Dent 1993:15:282-7.

16 Green JG, Durham TM. Application of INSTAT hemostat in the control of gingival haemorrhage in the patient with thrombocytopenia. Oral Surg Oral Med Oral Pathol 1991;71:27-30

17 Sindet-Pedersen S, Stenbjerg S, Ingerslev J. Control of gingival haemorrhage in haemophilic patients by inhibition of fibrinolysis with tranexamic acid. J Periodont Res 1988;23:72-4.

18 Brower CL, Thompson AR. Hemophilia B [Christmas disease, factor IX deficiency]. GeneReviews. http://www.ncbi.nlm.nih.gov/bookshelf/br.fcgi?book=gene\&amp; part=hemo-b (accessed 16 Jul 2009).

Copyright 2015 BMJ Publishing Group. All rights reserved. For permission to reuse any of this content visit http://group.bmi.com/group/rights-licensing/permissions.

BMJ Case Report Fellows may re-use this article for personal use and teaching without any further permission.

Become a Fellow of BMJ Case Reports today and you can:

- Submit as many cases as you like

- Enjoy fast sympathetic peer review and rapid publication of accepted articles

- Access all the published articles

- Re-use any of the published material for personal use and teaching without further permission

For information on Institutional Fellowships contact consortiasales@bmjgroup.com

Visit casereports.bmj.com for more articles like this and to become a Fellow 